\title{
ПРОТЕЗИРОВАНИЕ ЗУБОВ С ПОМОЩЬЮ КЕРАМИЧЕСКИХ ВИНИРОВ
}

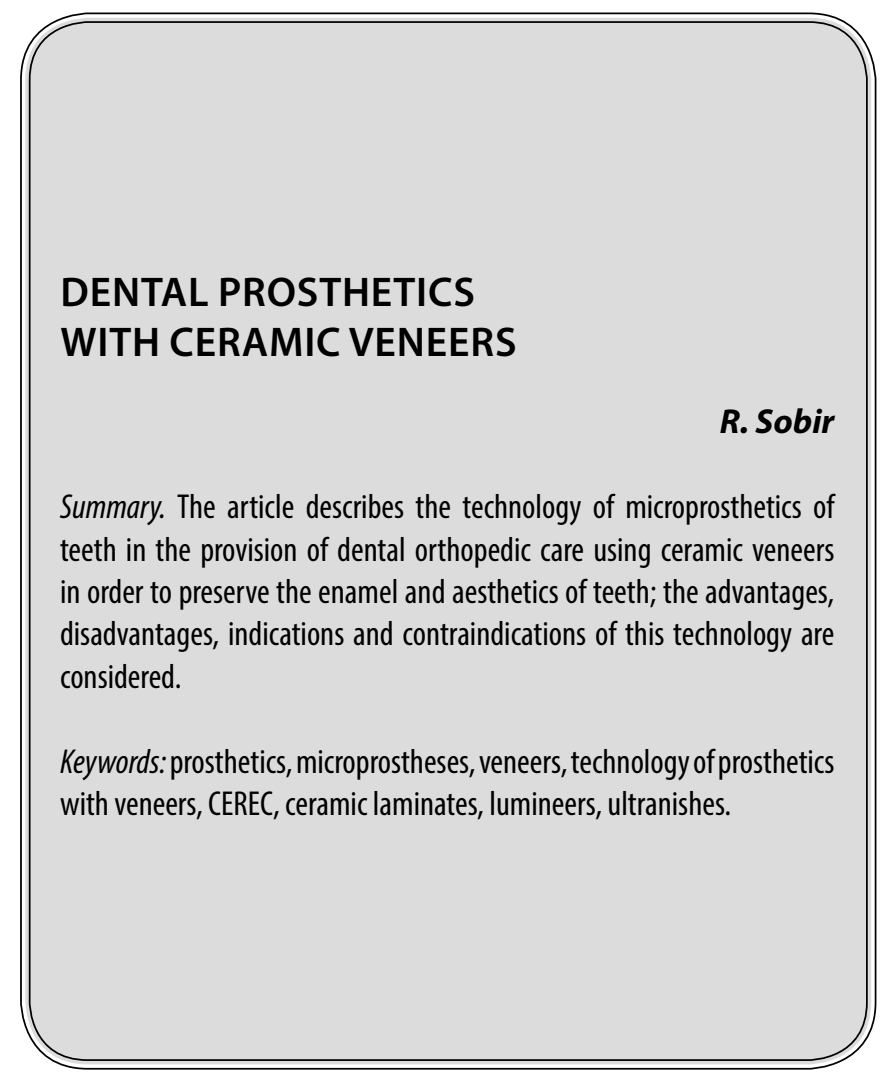

O дной из основных задач в ортопедической стоматологии является эстетическая реставрация дефектов зубных рядов. На данный момент эта задача успешно решается с помощью применения цельнокерамических материалов (безметалловой керамики). Данная технология используется в зубном протезировании в виде различных конструкций - зубных виниров, люминиров и других - во всех случаях, когда необходимо заменить старые конструкции или обширные пломбы и продлить жизнеспособность зуба с минимальными потерями твёрдых тканей и максимальным сохранением эстетики зубов.

\section{Обшие свеАения}

Виниры (veneer, laminate) - это тонкие фарфоровые (керамические) или композитные пластинки, замещающие вестибулярную (внешнюю) поверхность зуба, другими словами, виниры представляют собой зубные накладки. Полное название метода - veneer porcelain (фарфоровая облицовка). Винир - микропротез, восстанавливающий анатомическую форму зуба. Виниры позволяют наиболее щадящим способом улучшить эстетику зубов $[3,6]$.
Собир Ромиш Комолзод

К.м.н., дочент, АУ Чувашии «Институт усовершенствования врачей» Минздравсочразвития

Чувашии

rom-sobir@yandex.ru

Аннотация. Приведено описание технологии микропротезирования зубов при оказании стоматологической ортопедической помощи с применением керамических виниров в целях сохранения эмали и эстетики зубов; рассмотрены преимущества, недостатки, показания и противопоказания данной технологии.

Ключевые слова: протезирование, микропротезы, виниры, технология протезирования винирами, CEREC, керамические ламинаты, люминиры, ультраниры.

Толщина виниров составляет в среднем 0,5 мм, благодаря этому они, как и природная эмаль зуба, прозрачны, свет отражается не от них, а от внутренних тканей самого зуба, поэтому зубы, покрытые винирами, ничем не отличаются от «родных» натуральных зубов.

Винирами обычно покрывается передние зубы (резцы и клыки) и боковые (премоляры и моляры - не всегда). Изготавливаются виниры в соответствии с формой, цветом зубов пациента и его пожеланиями.

Виниры позволяют полностью исправлять нарушения формы или цвета зуба, а также защищают зубы от многих отрицательных факторов. В результате восстановленный зуб обретает прочность и не отличается от остальных зубов.

Виниры бывают различных видов - полимерные (композитные, пластмассовые) и неполимерные (фарфоровые, керамические). Полимерные виниры изготавливаются из композитных материалов и обладают рядом существенных недостатков, таких как невысокая прочность, низкая эстетика, возможность возникновения аллергических реакций и пр. 
По данной причине в статье рассматриваются именно керамические виниры.

\section{Керамические виниры}

Неполимерные виниры изготавливаются из керамики или медицинского фарфора только в условиях зуботехнической лаборатории [1, 2]. Их используют при необходимости реставрации как одиночных, так и значительного количества зубов.

Такие виниры позволяют устранить многие дефекты зубного ряда: неправильную форму, уклон зубов, трещины, сколы и потертость эмали, а также восстановить естественный цвет потемневших зубов, закрыть промежутки между зубами и пр.

Изготовление керамических виниров, как правило, требует несколько визитов пациента и может занять время около одной недели.

В первое посещение врач-стоматолог-ортопед должен осмотреть пациента на предмет отсутствия кариеса, воспаления и кровоточивости дёсен, а также определить цвет естественных зубов, для чего применяется специальная шкала с 15 основными оттенками. Кроме того, чтобы достичь максимально приближенного оттенка, совпадающего с эмалью соседних коронок зубов, используется специальная краска. От правильного выбора цвета будет зависеть естественность будущего результата.

После этого в соответствии с формой будущего винира осуществляется препарирование (обработка) передней поверхности зуба на определенную толщину, в среднем 0,5-0,7 мм, чтобы обеспечить место для будущего винира (толщина, т.е. поперечный размер пластинок виниров составляет от 0,4 до 1,5 мм, а в отдельных случаях до 2 мм). Препарирование зубов проводится под местной анестезией. С обработанной передней части зуба врач с помощью силиконового материала снимает анатомические оттиски (слепки) зубов, которые передаёт в зуботехническую лабораторию.

На время изготовления винира для защиты препарированного зуба от скапливания налёта на его шероховатой поверхности и других внешних раздражающих факторов устанавливаются временные виниры из пластмaccы.

В следующее посещение проводится примерка композиции будущего винира из воска для того, чтобы согласовать с пациентом форму будущего винира. Далее зубной техник в зуботехнической лаборатории изготавливает уже постоянный винир одном из методов:
- наслоение керамических порошков (классический метод);

- литье под давлением (пресс-керамика);

- фрезерование из цельных блоков, например, литий-дисиликатного блока.

На следующем этапе происходит примерка готового винира, во время которой необходимо убедиться в правильности выбранного цвета и формы. Затем зубной техник при необходимости подкрашивает его специальными красками под цвет рядом стоящих зубов. На этом этапе врач устраняет имеющиеся недостатки винира, подгоняет микропротез, проверяет прикус и только после этого принимает решение об установке винира на зуб, т.к. после окончательной фиксации винира коррекция уже практически невозможна. Далее поверхность отпрепарированного зуба очищают от цемента, примерочного геля и других посторонних включений. Затем поверхность зуба протравливают фосфорной кислотой (37\%), что повышает прочность прикрепления винира к зубу. Кислоту смывают обильным количеством воды. Перед фиксацией винира поверхность зуба высушивается и наносится специальный гель (праймер) для уменьшения чувствительности и защиты от возможного проникновения микрофлоры в ткани зуба. Через 30 секунд поверхность зуба ещё раз высушивается, после чего дополнительно наносится адгезив (клей), который полимеризуется лампой. Для улучшения ретенции возможна предварительная пескоструйная обработка контактной поверхности винира.

Фиксация готового изделия производится следующзим образом:

- проводится протравливание внутренней поверхности винира $10 \%$ плавиковой кислотой в течение определённого времени (1-4 мин);

- винир тщательно промывается струей воды, помещается в ультразвуковую ванну на 2 минуты для удаления остатков геля и просушивается воздухом;

- на внутреннюю поверхность винира наносится фиксирующий материал и винир накладывается на зуб;

- до окончания полимеризации (затвердевания) удаляются излишки материала;

- с помощью специального цемента (жидкотекучего композиционного светоотверждаемого материала) винир приклеивается к зубу, при этом происходит прочная фиксация винира;

- после полимеризации фиксирующего материала проводятся шлифование и полирование так называемого клеевого шва.

Также непрямой керамический винир может быть изготовлен за одно посещение методом компьютер- 
ного моделирования и фрезерования - CEREC (англ. Chairside Economical Restorations of Esthetic Ceramic, рус. аппарат для экономичной и эстетической керамической реставрации). Это комплекс из технологии, оборудования и материалов для изготовления зубных микропротезов (виниров, вкладок и накладок), вытачиваемых из керамических блоков с применением специализированной CAD/CAM системы $[3,4]$.

При использовании данной технологии вместо снятия анатомического слепка (оттиска) используют специальную трёхмерную сканирующую камеру, с помощью которой создаётся трёхмерная компьютерная модель (оптический оттиск) с высоким разрешением, что резко повышает её качество. Затем модель передаётся в шлифовальный блок, который под управлением компьютера из заготовки подходящего цвета и размера в течение 10-15 минут вытачивает микропротез. После этого врач приступает к примерке (припасовке) и фиксации готовой конструкции.

\section{Преимушества и неАостатки} керамических виниров

Основным достоинством керамических (фарфоровых) виниров перед аналогами из других материалов (композитных и т.п.) заключается в том, их воздействие на пародонт практически отсутствует, так как края отреставрированной конструкции нет необходимости располагать под десной. К тому же коэффициент теплового расширения керамики и природных зубов практически совпадает [1].

Помимо этого, керамические обладают следующими преимуществами:

- повышенная эстетика (стабильность цвета, постоянный блеск);

- стабильность формы (низкая стираемость);

- биоинертность;

- устойчивость к пищевым красителям;

- прочность и долговечность.

Кроме того, уменьшается подверженность зубов кариесу, т.к. при фиксации зуб подвергается фторированию, поскольку в составе цементирующего состава содержится фтор.

Виниры не требуют какого-либо специального ухода, достаточна регулярная чистка их поверхности зубной щеткой и флоссами - так же, как и остальных зубов.

При соблюдении правил гигиены и рекомендаций стоматолога (отказаться от привычек грызть ногти, семечки, орехи и др.) керамические виниры могут служить более двадцати пяти лет.
Из недостатков керамических виниров можно отметить:

- низкий эффект ремонта при сколе (обломе) части винира;

- длительное время изготовления (по сравнению с композитными);

- невозможность снятия конструкции после постоянной фиксации;

- высокая стоимость.

\section{Показания и противопоказания} к применению виниров

К применению виниров существует ряд показаний и противопоказаний.

\section{Показания}

Использование виниров в стоматологии позволяет добиться высокого эстетического эффекта при различных дефектах поверхности и цвета зубов, таких как:

- измененный цвет зубов, не поддающийся коррекции методами отбеливания: пигментные пятна эмали, возрастные изменения цвета, пигментированные трещины эмали, флюороз и «тетрациклиновые зубы»;

- измененная форма зубов вследствие травмы или лечения корневого канала, клиновидные дефекты;

- зубы с нарушением развития эмали (несовершенный амелогенез, гипоплазия эмали) и зубы с нарушением развития формы (шиповидные зубы);

- повороты зубов вокруг своей оси и их наклоны;

- прогрессирующая стираемость зубов по окклюзии;

- промежутки между зубами (диастема, трема);

- необходимость коррекции эстетики фронтального участка зубного ряда изменением анатомической формы коронок отдельных зубов (при адентии либо наличии ретинированного зуба);

- наличие множественных небольших по размеру пломб, старых пломб, отличающихся по цвету от ткани зуба.

\section{Противопоказания}

Изготовление виниров противопоказано или нежелательно при функциональной недостаточности зубочелюстной системы пациента. Основное правило: прежде чем заниматься эстетикой, необходимо восстановить функцию. Протезирование при отсутствии зубов в боковых отделах либо восстановление их жевательной эффективности должно быть приоритетной задачей стоматолога. 
Керамические виниры нельзя применять при следующих состояниях:

- прогрессирующие заболевания периодонта и кариозные болезни зубов;

- значительные дефекты эмали либо значительные её стирания, сошлифовывания;

- значительные дефекты коронки зуба (разрушение более половины её размера);

- парафункция жевательной мускулатуры (к примеру, бруксизм).

\section{Современные керамические виниры}

Современная стоматология предлагает альтернативные разновидности классических виниров - это керамические ламинаты, люминиры, ультраниры. В настоящей статье также необходимо привести их краткую характеристику.

\section{Керамические ламинаты}

Керамические ламинаты изготавливаются из прессованной керамики и фиксируются на адгезивный материал, соединяющий ламинат с естественным зубом в единый монолит. Таким образом, возможность откола винира (ламината) от зуба сводится практически к нулю. При использовании ламинатов нет необходимости в создании выраженного пришеечного уступа зуба и его обработки ниже десневого края $[2,4,5]$. В остальном их характеристики не отличаются от обычных виниров.

\section{^юминиры}

Люминиры (Lumineers) представляют собой тончайшие (толщиной не более 0,2-0,3 мм) фарфоровые пластинки, которые замещают внешний слой зубов. Благодаря такой толщине их практически невозможно идентифицировать на зубной поверхности. Данная технология запатентована компанией Cerinate (США, штат Калифорния) и изготовление таких пластинок происходит исключительно в лаборатории данной компании (США) по оптическим оттискам зубов [6]. В связи с этим общий срок восстановления зубов люминирами составляет не менее одного месяца, соответственно повышается их стоимость.

Люминиры максимально приближены по своим характеристикам к эмали живого зуба. Такие конструкции чаще всего не требуют предварительного препарирования зубов (за исключением индивидуальных люминиров, для которых можно провести небольшую коррекцию зубов). Люминиры, в отличие от виниров, можно снимать при необходимости. Конструкция люминиров намного прочнее, чем обычных виниров - это исключает возможность образования на поверхности люминиров микротрещин.
Таким образом, при использовании люминиров достигаются необходимый эстетический результат, наименьшее травмирование зуба при установке, а также износостойкость, надёжность и долговечность. Срок эксплуатации (службы) люминиров так же, как и у керамических виниров, составляет более двадцати пяти лет $[3,6]$.

Тем не менее, люминиры имеют достаточно высокую стоимость, а из-за отсутствия препарирования зубы с ними немного крупнее естественных. Кроме того, не рекомендуется их применение в случаях «пятнистой» или разноцветной эмали.

\section{Ультраниры}

Ультраниры представляют собой керамические изделия, которые крепятся к передним зубам верхнего или нижнего ряда и являются более дешёвыми (доступными) аналогами люминиров и по всем характеристикам очень похожи на них. Разница между ними заключается в том, что они изготавливаются в обычных зуботехнических лабораториях из сверхпрочной прессованной керамики $[4,5]$. Поэтому сроки изготовления ультраниров существенно меньше люминиров, что позволяет обеспечить ультратонкими накладками достаточно большое количество пациентов.

Максимальная толщина подобных накладок обычно не превышает 0,5 мм, а в среднем составляет 0,3-0,4 мм, что чуть толще, чем люминиров, но меньше, чем у виниров. При применении ультраниров требуется минимальное препарирование вестибулярной поверхности зуба. Однако ультраниры имеют относительно небольшой срок службы конструкции, зависящий от используемого материала и составляющий в среднем 10-12 лет.

Следует отметить, что при выборе конкретного вида накладок мнение о том, что виниры лучше, чем люминиры и ультраниры, или наоборот, является ошибочным всё зависит от клинической картины и ожидаемых результатов на ортопедическом приёме.

\section{Эак^ючение}

Керамические виниры способны полностью имитировать собственные ткани зуба, а также позволяют полностью исправлять нарушения формы или цвета зуба. К тому же современные технологии позволяют придать виниру любые оттенки, которые будут имитировать цвет и прозрачность соседних здоровых зубов. Кроме того, такие виниры защищают зубы от многих отрицательных факторов. То есть, помимо внешней привлекательности, данные конструкции обладают высокой прочностью и надёжностью. 


\section{ЛИТЕРАТУРА}

1. Ортопедическая стоматология. Прикладное материаловедение. Учебник / В. Н. Трезубов, Л. М. Мишнев, В. В. Трезубов.— М.: МЕДпресс-информ, 2017.

2. Стоматологическое материаловедение. Наглядное учебное пособие / под ред. Энтони фон Фраунхофера, — М.: ГЭОТАР-Медиа, 2017.

3. Гюрель Г. Керамические виниры. Искусство и наука / Г. Гюрель.—М.: Азбука стоматолога, 2007.

4. Виниры (ламинаты): учеб.-метод. пособие / С. А. Наумович и др.-Минск: БГМУ, 2013.

5. Петрикас 0. А. Лечение больных с поражением твердых тканей зубов винирами. - Тверь: ТверьГМУ, 2009.

6. Beier U. S. Clinical performance of porcelain laminate veneers for up to 20 years / U. S. Beier, I. Kapferer, D. Burtscher, H. Dumfahrt. —Int J Prosthodont, 2012.

(с Собир Ромиш Комолзод ( rom-sobir@yandex.ru).

Журнал «Современная наука: актуальные проблемы теории и практики»

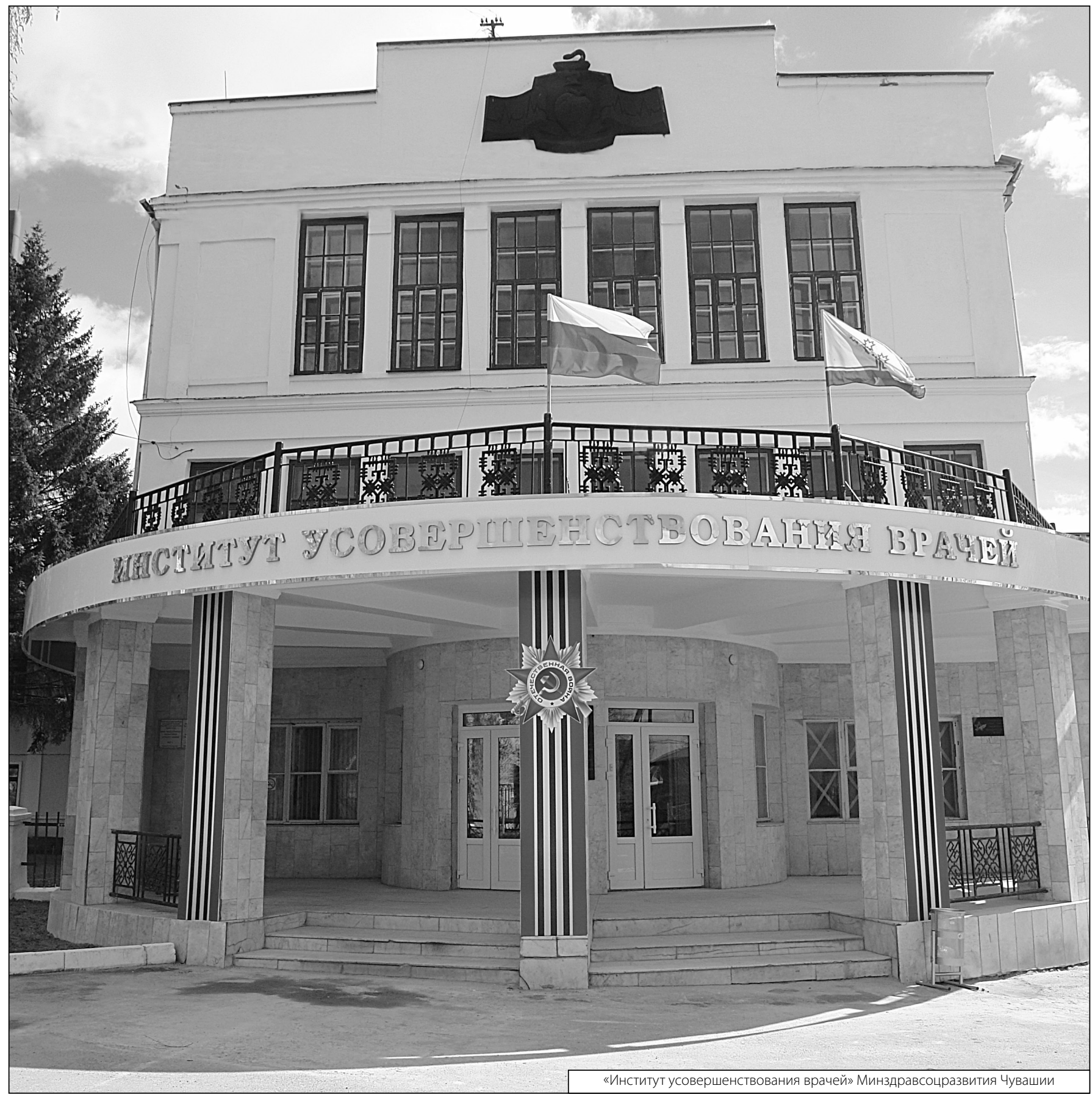

